\title{
ОТДАЛЕННЫЕ ИСХОДЫ И ДИНАМИКА ФАРМАКОТЕРАПИИ У ПАЦИЕНТОВ С ФИБРИЛЛЯЦИЕЙ ПРЕДСЕРДИЙ ПО ДАННЫМ ИССЛЕДОВАНИЯ РЕКУР-ФП
}

\author{
(ㄱ Польшакова И.Л., Поветкин С.В.
}

\author{
Курский государственный медицинский университет (КГМУ) \\ Россия, 305041, Курская область, г. Курск, ул. К. Маркса, д. 3
}

Цель: изучить в рамках исследования РЕКУР-ФП исходы через 9 и 18 месяцев и динамику медикаментозного лечения при реализации компонентов интегрированного подхода у пациентов с фибрилляцией предсердий (ФП) в условиях регионального центра.

Материалы и методы. Исследование проведено в три этапа: 1 - включение в работу 896 пациентов с ФП, наблюдающихся в медицинских организациях (MO) г. Курска и Курской области с сентября 2015 г. по август 2016 г.; 2 - получение посредством телефонного контакта сведений об исходах и фармакотерапии пациентов через 9 месяцев; 3 - через 18 месяцев после набора пациентов, проведение объема исследований, аналогичного второму этапу. После 9 месяцев наблюдения проведено внедрение системы поддержки принятия фармакотерапевтических решений по антитромботической терапии пациентов с ФП (СППР-ФП) в МО Курской области.

Результаты. На 2 и 3 этапе работы получена информация о 532 и 436 больных, из них скончалось 60 и 37 человек соответственно. Причина смерти большинства пациентов - кардиоваскулярная патология. Среди выживших больных каждый третий нуждался в госпитализации преимущественно из-за декомпенсации хронической сердечной недостаточности или пароксизма ФП. Через 18 месяцев наблюдения частота назначения антиагрегантных препаратов (57,1\%), ингибиторов ангиотензинпревращающего фермента (55,6\%), статинов (53,9\%) и диуретиков $(48,6 \%)$ была достоверно ниже, чем на первом этапе исследования. Значимо вырос уровень использования оральных антикоагулянтов (ОАК), за счет периода после внедрения СППР-ФП (от 18,3\% исходно до 26,1\% на 3 этапе работы). У пациентов, принимающих ОАК, частота фатальных исходов была достоверно ниже, чем у больных без антикоагулянтной терапии, на период 9 и 18 месяцев наблюдения.

Заключение. В работе показана целесообразность использования СППР-ФП в составе интегрированного подхода к ведению пациентов с ФП для оптимизации антитромботической терапии указанного контингента больных.

Ключевые слова: фибрилляция предсердий; исходы; региональное исследование; лечение; интегрированный подход.

Польшакова Инна Леонидовна - ассистент кафедры клинической фармакологии, КГМУ, г. Курск. ORCID iD: 0000-00025083-3137. E-mail: potolowa@mail.ru (автор, ответственный за переписку)

Поветкин Сергей Владимирович - д-р мед. наук, профессор, зав. кафедрой клинической фармакологии, КГМУ, г. Курск. ORCID iD: 0000-0002-1302-9326. E-mail: clinfarm@kursknet.ru

Одним из наиболее встречающихся в типичной практике врача нарушением ритма сердца является фибрилляция предсердий (ФП). Ее распространенность в общей популяции составляет около $2 \%$. Этот показатель увеличивается с возрастом, а также при наличии артериальной гипертензии (АГ), хронической сердечной недостаточности (ХCH), ишемической болезни сердца (ИБС), сахарного диабета и других ассоциированных состояний. Наиболее частые осложнения ФП - тромбоэмболические события, в том числе ишемический инсульт, который нередко заканчивается смертельным исходом. В большей степени летальность у больных с ФП ассоциируется с прогрессирующей сердечной недостаточностью и внезапной сердечной смертью. Тактика ведения пациентов с ФП, для предотвращения вышеописанных осложнений, в т. ч. и фатальных, изложена в действующих клинических рекомендациях и должна включать в себя назначение антикоагулянтной и антиаритмической терапии, лечение сопутствующей патологии $[1,12]$. Однако ситуация в ре- альной клинической практике далека от идеальной. Данные отечественных и зарубежных исследований, включающих пациентов с ФП, свидетельствуют о недостаточном уровне назначения препаратов, обладающих положительным влиянием на прогноз у исследуемых больных $[2,9,11]$. Существуют различные подходы к оптимизации фармакотерапии, одним из которых может быть проведение неинтервенционного наблюдательного клинического исследования с включением элементов комплексного подхода к лечению, в виде системы поддержки принятия фармакотерапевтических решений по антитромботической терапии больных с ФП (СППР-ФП). Данные аспекты наиболее важны в регионах с высоким уровнем сердечнососудистой смертности. В Курской области данный показатель в 2015 году на четверть превышал средний уровень по России - 791,0 на 100 тыс. человек населения [8]. В настоящее время смертность от болезней системы кровообращения в нашем регионе несколько снизилась, однако продолжает превышать средние показа- 
тели по стране. В 2018 году показатель смертности в Курской области - 705,0 на 100 тыс. населения, с января по август 2019 г. - 711,4 на 100 тыс. населения [10].

Цель работы: изучить в рамках проспективного исследования РЕКУР-ФП исходы через 9 и 18 месяцев и динамику медикаментозного лечения при реализации компонентов интегрированного подхода у пациентов с ФП в условиях регионального центра.

\section{МАТЕРИАЛЫ И МЕТОДЫ ИССЛЕДОВАНИЯ}

Общая концепция исследования РЕКУР-ФП включала в себя несколько этапов. Первый заключался в наборе базы данных пациентов включено 896 больных с ФП старше 18 лет, наблюдавшихся в 14 медицинских организациях города Курска и районов Курской области, за период с сентября 2015 г. по август 2016 г. Полученные сведения вносили в разработанную регистрационную форму пациента, а затем в электронную базу. Для сохранения конфиденциальности информации проводилось кодирование персональных данных пациентов. На втором этапе осуществлялся телефонный контакт с больными (либо их родственниками) для получения сведений об исходах, изменениях в лечении и госпитализациях через 9 месяцев от момента завершения набора пациентов. Аналогичным образом через 18 месяцев после окончания формирования базы данных был проведен третий этап, позволявший реализовать задачи, идентичные второму этапу, но в отношении последних 9 месяцев наблюдения.

После завершения второго этапа исследования, в практическую деятельность медицинских организаций Курской области в качестве компонентов интегрированного подхода к ведению больных с ФП было внедрено два вида информационных ресурсов для врачей: руководство СППР-ФП, изданное типографским способом, и аналогичное по содержательной составляющей приложение для смартфонов (на базе Android), эффективность использования которых оценивалась на сроке 18 месяцев мониторирования пациентов $[4,7]$.

В наблюдаемой когорте пациентов в качестве исхода («конечной точки») рассматривали «смерть от любой причины».

Для статистической обработки данных применяли методы описательной статистики. Сравнение дискретных величин в системе четырехпольных таблиц осуществлялось с помощью критерия $\chi^{2}$ с его коррекцией на непрерывность по Йетсу. Статистически значимыми считали различия при значениях двустороннего $\mathrm{p}<0,05$.
Результаты (для абсолютных количественных параметров), в зависимости от типа распределения, представлены в виде Ме [25-75 квартили] или $\mathrm{M} \pm \mathrm{SD}$; относительные показатели выражены в процентах.

\section{РЕЗУЛЬТАТЫ ИССЛЕДОВАНИЯ И ИХ ОБСУЖДЕНИЕ}

Общая характеристика больных с ФП, включенных в исследование, подробно описана ранее $[5,6]$. На втором и третьем этапе исследования удалось установить данные о 532 и 436 пациентах, среди которых было 50,8\% и 49,8\% мужчин соответственно. Через 9 месяцев наблюдения летальный исход был зафиксирован у 60 человек, через 1,5 года - у 37 пациентов. Причинами фатальных исходов в $60 \%$ и $54,1 \%$ случаев на 2 и 3 этапе наблюдения соответственно была сердечно-сосудистая патология, в числе которой чаще всего зафиксирована декомпенсация ХСН и мозговой инсульт (МИ). Среди выживших пациентов за 9 и 18 месяцев наблюдения перенесли МИ - 13 и 7 человек, инфаркт миокарда - 5 и 4, интервенционное вмешательство по поводу кардиоваскулярной патологии - 10 и 5, тромбоэмболию легочной артерии по 1 пациенту соответственно. В стационарном лечении за предшествующий 9-месячный период нуждалось 36,9\% больных на втором этапе работы и 30,6\% пациентов через 18 месяцев наблюдения. На протяжении всего исследования причиной для госпитализации чаще всего были пароксизмы ФП и декомпенсация ХСН.

Среднее количество препаратов для лечения сердечно-сосудистых заболеваний (СС3) значимо не изменилось: исходно использовали 5 [4-6], через 9 месяцев наблюдения 5 [4-6] препаратов, полтора года - 5 [3-6] лекарственных средств (ЛС). При сравнении частоты использования ЛС на втором этапе исследования с исходными данными регистрируется значимое уменьшение уровня антиагрегантных препаратов, статинов, ингибиторов ангиотензинпревращающего фермента (иАПФ) и диуретиков. Другие изменения в терапии исследуемого контингента больных были недостоверны. Через 18 месяцев наблюдения отмечается дальнейшее значимое уменьшение частоты использования вышеперечисленных групп препаратов по сравнению с исходными данными. Следует отметить, что показатели использования диуретиков достоверно снизились и за период между 2 и 3 этапом исследования. Колебание уровня потребления антиаритмических препаратов, сердечных гликозидов, антагонистов рецепторов ангиотензина II (APA II), бета-адреноблокаторов (БАБ), блокаторов кальциевых каналов (БКК), миокардиальных 
цитопротекторов и антагонистов минералокортикоидных рецепторов (АМКР) было недостоверно в сравнении с результатами 1 и 2 этапа работы. Частота назначения оральных антикоагулянтов (ОАК) значимо увеличилась через полтора года наблюдения (см. табл. 1).

Из группы ОАК пациенты использовали новые пероральные антикоагулянты (НОАК) и варфарин, причем их соотношение значительно не изменилось: исходно - $47,6 \%$ и $52,4 \%$, через 9 месяцев - 46,7\% и 53,3\%, 18 месяцев - 49,0\% и $51,0 \%$ соответственно. Представителями НОАК были ривароксабан и дабигатран, причем в ходе динамического наблюдения имелась тенденция к уменьшению доли последнего в структуре этого класса препаратов: исходно - 34,6\% и $65,4 \%$, через 9 месяцев - 39,5\% и 65\%, 18 месяцев $51,0 \%$ и $49 \%$ соответственно.

Проведенный анализ частоты летального исхода среди пациентов с ФП в зависимости от приема ОАК через 9 и 18 месяцев наблюдения показал, что значимо чаще фатальный исход регистрировался у пациентов, не получающих антикоагулянтную терапию (см. рис. 1). Данные различия были также верифицированы с помощью дисперсионного анализа, который подтвердил достоверное влияние использования ОАК на уровень смертности на сроке $9(\mathrm{~F}=7,05$; $\mathrm{p}=0,008)$ и 18 месяцев $(\mathrm{F}=9,67 ; \mathrm{p}=0,002)$ наблюдения. Доля пациентов с ФП, употребляющих ОАК, среди умерших больных за все время исследования составляла 6,2\% (по 3 человека на 2 и 3 этапе работы соответственно).

По результатам амбулаторного проспективного исследования РЕКУР-ФП установлено, что среди пациентов с ФП г. Курска и районов Курской области в большинстве случаев причиной смертельного исхода в течение 1,5 лет наблюдения являются ССЗ. Среди них лидируют декомпенсация ХCH и МИ. Последний был наиболее частым из регистрируемых нефатальных сердечно-сосудистых осложнений. Госпитализация в течение всего исследования требовалась по большей части из-за пароксизма ФП или декомпенсации ХCH. Фармакотерапия исследуемых больных претерпела следующие значимые изменения за период 18-месячного наблюдения по сравнению с исходными данными: снизилась частота использования антитромбоцитарных препаратов, статинов, иАПФ, диуретиков. Вышеописанную негативную динамику возможно обьяснить несколькими причинами: коморбидная патология у пациентов с ФП обусловливает необходимость назначения большого количества препаратов, что вызывает низкую приверженность к лечению; при включении пациентов в исследование регистрировались назначения врача из амбулаторной карты, а через 9 и 18 ме- сяцев, при телефонном контакте, фиксировались реально употребляемые больными ЛС. Внедрение компонентов интегрированного подхода к лечению пациентов с ФП, в совокупности с другими видами мероприятий, проводимыми в регионе и направленными на оптимизацию фармакотерапии указанной категории больных, способствовало достоверному увеличению уровня потребления ОАК. Однако, частота использования антикоагулянтов через 1,5 года наблюдения составила всего 26,1\%, что не соответствует требованиям национальных клинических рекомендаций. Установлено достоверное уменьшение частоты летальных исходов в группе пациентов с ФП, принимавших ОАК, что свидетельствует о положительном влиянии антикоагулянтной терапии на смертность исследуемого контингента больных. Ограничением исследования, которое могло повлиять на его результаты, стал факт наличия информации о статусе пациентов через 9 и 18 месяцев наблюдения у 59,3\% и 55,4\% больных соответственно.

Полученные нами результаты согласуются с данными отечественных исследований, включающих пациентов с ФП. Так, в амбулаторном регистре РЕКВАЗА $(\mathrm{n}=530)$ сердечно-сосудистая патология стала причиной летального исхода 30 из 39 умерших больных. Из нефатальных кардиоваскулярных осложнений за 12 месяцев наблюдения отмечены: инфаркт миокарда у 0,6\%, МИ - 3,4\%, операции по поводу СС3 - 0,4\% больных. Высокие показатели сердечнососудистой смертности в этом исследовании, возможно, связаны с наличием коморбидных CC3 у подавляющего большинства (98,3\% АГ, 97,2\% ИБС, 96,8\% ХСН) пациентов с ФП [2]. В регистре РЕКВАЗА-КУРСК $(\mathrm{n}=480)$ скончались 163 пациента с ФП, из них 75,5\% от кардиоваскулярной патологии. Наиболее частыми причинами смерти были МИ (32,5\%), инфаркт миокарда $(17,2 \%), \mathrm{XCH}(16,6 \%)$. Следствием различий вышеперечисленных данных с результатами исследования РЕКУР-ФП, по-видимому, являются госпитальный характер регистра, наличие ИБС у всех исследуемых пациентов, больший срок проспективного наблюдения $(28,2 \pm 6,7$ месяца) [3]. В госпитальном регистре РЕКВАЗАКЛИНИКА проанализировано изменение фармакотерапии у 285 пациентов с ФП, ХСН, ИБС и

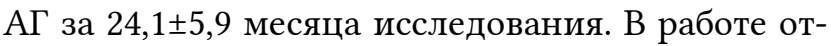
мечается высокий уровень назначения прогнозмодифицирующей терапии: через 2 года наблюдения БАБ использовали 92,8\% больных, иАПФ/АРА II - 92\%, статины - 62,8\%, ОАК - $82 \%$. Отмечено достоверное снижение уровня потребления статинов и ОАК по сравнению с госпитальным этапом регистра. 
Динамика частоты назначения групп препаратов для лечения ССЗ в течение всего исследования Dynamics of the frequency of prescribing drugs for the treatment of cardiovascular disease throughout the study

\begin{tabular}{|c|c|c|c|}
\hline $\begin{array}{c}\text { Группа ЛС } \\
\text { Group of drugs } \\
\end{array}$ & $\begin{array}{c}1 \text { этап }(\mathrm{n}=896), \% \\
1 \text { stage }\end{array}$ & $\begin{array}{c}2 \text { этап }(\mathrm{n}=472), \% \\
2 \text { stage }\end{array}$ & $\begin{array}{c}3 \text { этап }(\mathrm{n}=399), \% \\
3 \text { stage }\end{array}$ \\
\hline $\begin{array}{l}\text { иАПФ } \\
\text { Angiotensin converting enzyme inhibitors }\end{array}$ & 67.7 & $58.1^{* * * 1}$ & $55.6^{* * * 1}$ \\
\hline $\begin{array}{l}\text { APA II } \\
\text { Angiotensin II receptor blockers }\end{array}$ & 16.2 & 15.5 & 17.0 \\
\hline $\begin{array}{l}\text { БАБ } \\
\text { Beta blockers }\end{array}$ & 65.2 & 61.7 & 63.4 \\
\hline $\begin{array}{l}\text { БКК } \\
\text { Calcium channel blockers }\end{array}$ & 16.3 & 16.1 & 16.3 \\
\hline $\begin{array}{l}\text { Антиаритмики } \\
\text { Antiarrhythmic drugs }\end{array}$ & 31.8 & 33.3 & 30.6 \\
\hline $\begin{array}{l}\text { Сердечные гликозиды } \\
\text { Cardiac glycosides }\end{array}$ & 26.5 & 23.3 & 23.1 \\
\hline $\begin{array}{l}\text { Статины } \\
\text { Statins }\end{array}$ & 64.7 & $54.2^{* * *} 1$ & $53.9^{* * * 1}$ \\
\hline $\begin{array}{l}\text { Миокардиальные цитопротекторы } \\
\text { Myocardial cytoprotectors }\end{array}$ & 7.9 & 7.2 & 9.3 \\
\hline $\begin{array}{l}\text { AMKP } \\
\text { Mineralocorticoid receptor antagonists }\end{array}$ & 52.8 & 49.6 & 47.9 \\
\hline $\begin{array}{l}\text { Диуретики } \\
\text { Diuretics }\end{array}$ & 62.1 & $56.1^{*} 1$ & $48.6^{* * *} 1,{ }^{*} 2$ \\
\hline $\begin{array}{l}\text { Антиагреганты } \\
\text { Antiplatelet drugs }\end{array}$ & 68.5 & $60.4^{* * 1}$ & $57.1^{* * *} 1$ \\
\hline $\begin{array}{l}\text { OAK } \\
\text { Oral anticoagulants (OAC) }\end{array}$ & 18.3 & 19.5 & $26.1^{* *} 1{ }^{*} 2$ \\
\hline
\end{tabular}

Примечание: различия достоверны между группами: * $-\mathrm{p}<0,05,{ }^{* *}-\mathrm{p}<0,01,{ }^{* * *}-\mathrm{p}<0,001$.

Note: differences are significant between groups: ${ }^{*}-\mathrm{p}<0.05,{ }^{* *}-\mathrm{p}<0.01,{ }^{* * *}-\mathrm{p}<0.001$.

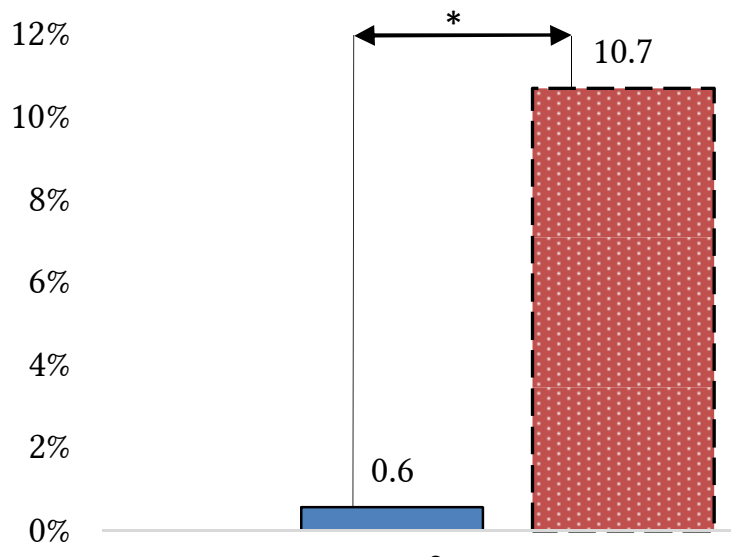

9 месяцев

9 months

$\square \mathrm{c} \mathrm{OAK}$ with OAC

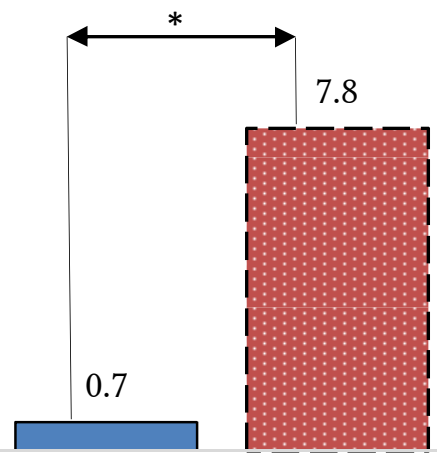

18 месяцев

18 months

[.] без ОАК

no OAC

Рис. 1. Число пациентов с летальным исходом в зависимости от факта приема ОАК на различных сроках наблюдения.

Примечание: различия достоверны между группами: * - $<<0,05$.

Fig. 1. The number of patients with a fatal outcome, depending on receiving $\mathrm{OAC}$ at various periods of observation.

Note: differences are significant between groups: ${ }^{*}-\mathrm{p}<0.05$. 
Причинами отличия вышеописанных данных от результатов нашей работы могут быть: меньшее количество исследуемых пациентов, наличие сочетанных ССЗ у 100\% больных, госпитальный вид регистра [9]. Зарубежное исследование GARFIELD-AF включает 52014 пациентов с впервые диагностированной неклапанной ФП из 35 стран мира. За год наблюдения летальный исход зафиксирован у 4,1\% больных, из них 37,3\% пациентов умерли от сердечно-сосудистых причин. Среди кардиоваскулярной патологии, приведшей к фатальному исходу, лидировала $\mathrm{XCH}$ и внезапная сердечная смерть. Нефатальный МИ за 1 год наблюдения зарегистрирован у $1,32 \%$ больных, инфаркт миокарда/острый коронарный синдром - 0,8\%. Факторами, обусловливающими отличия результатов этой работы, стали: большое количество исследуемых пациентов, низкая частота встречаемости коморбидной сердечно-сосудистой патологии $(\mathrm{XCH}-20 \%$, ИБС - 22\%) и впервые зарегистрированная форма ФП как критерий включения в исследование [11].

Таким образом, по данным амбулаторного проспективного исследования РЕКУР-ФП у пациентов с ФП за 18 месяцев наблюдения выявлено превалирование сердечно-сосудистых событий в структуре причин смерти, а также причин для стационарного лечения. Этот факт может быть обусловлен недостаточным уровнем использования препаратов, обладающих положительным влиянием на прогноз (в первую очередь ОАК) в течение всего исследования. Реализация отдельных компонентов интегрированного подхода, как составляющая системной оптимизации ведения больных с ФП, вносила определенный вклад в изменение антитромботической терапии, отражающееся в достоверном увеличении числа пациентов, принимающих ОАК, и снижении частоты использования антитромбоцитарных препаратов. Выявлено достоверное снижение смертности исследуемых больных, при условии приема ими ОАК. Результаты исследования свидетельствуют о необходимости более активного использования интегрированного подхода к ведению больных с ФП в реальной клинической практике.

\section{КОНФЛИКТ ИНТЕРЕСОВ}

Авторы декларируют отсутствие явных и потенциальных конфликтов интересов, связанных с публикацией настоящей статьи.

\section{ИСТОЧНИКИ ФИНАНСИРОВАНИЯ}

Авторы заявляют об отсутствии финансирования.

\section{СООТВЕТСТВИЕ ПРИНЦИПАМ ЭТИКИ}

Протокол исследования одобрен Региональным этическим комитетом при Курском государственном медицинском университете (протокол № 7 от 07.09.2015 г.). Каждым пациентом было подписано индивидуальное согласие на участие в исследовании.

\section{ЛИТЕРАTУPA/REFERENCES}

1. Диагностика и лечение фибрилляиии предсердий. Рекомендации ВНОК, РКО и АССX (2017). URL: https://vnoa.ru/upload/edition_june2017/4_fp.pdf (дата обращения 31.10.2019) [Diagnosis and treatment of atrial fibrillation. Recommendations of the VNOC, RKO and ACCC (2017). URL: https://vnoa.ru/upload/edition_june2017/4_fp.pdf (date of issue 31.10.2019) (in Russ.)]

2. Лукьянов М.М., Бойцов С.А., Якушин С.С., Марцевич С.Ю., Воробьев А.Н., Загребельный А.В., Харлап М.С., Переверзева К.Г. и др. Амбулаторнополиклинический регистр кардиоваскулярных заболеваний (РЕКВАЗА): данные проспективного наблюдения, оценка риска и исходы у больных с фибрилляцией предсердий. Рациональная фармакотерапия в кардиологии. 2014;10(5):470-480 [Loukianov M.M., Boytsov S.A., Yakushin S.S., Martsevich S.Yu., Vorobyev A.N., Zagrebelnyy A.V., Kharlap M.S., Pereverzeva C.G. et al. Outpatient registry of cardiovascular diseases (RECVASA): prospective follow-up data, estimation of risks and outcomes in patients with atrial fibrillation. Rational Pharmacotherapy in Cardiology. 2014; 10(5):470-480 (in Russ.)] DOI: 10.20996/1819-6446-2014-10-5-470480

3. Масленникова Ю.В., Михин В.П., Лукьянов М.М. Фатальные исходы у больных с сочетанием ишемической болезни сердца и фибрилляции предсердий (по данным регистра РЕКВАЗА ФПКУРСК). Профилактическая медицина. 2018; 21(2-2):17 [Maslennikova Yu.V., Mikhin V.P., Loukianov M.M. Fatal outcomes in patients with a combination of coronary heart disease and atrial fibrillation (according to the register of RECVASA AFKURSK). Profilakticheskaya meditsina. 2018; 21(2-2):17 (in Russ.)]

4. Поветкин С.В., Польшакова И.Л. Система поддержки принятия фармакотерапевтических решений по антитромботической терапии больных с фибрилляцией предсердий в различных клинических ситуациях. Практическое руководство для врачей, ординаторов, студентов медицинских вузов. Курск: КГМУ, 2017. 29 с. [Polshakova I.L., Povetkin S.V. Pharmacotherapeutic decision support system for antithrombotic therapy of patients with atrial fibrillation in various clinical situations. Practical guide for doctors, residents, medical students. Kursk: KSMU, 2017. 29 p. (in Russ.)]

5. Польшакова И.Л., Поветкин С.В. Сравнительная многоаспектная характеристика пациентов с фибрилляцией предсердий, наблюдающихся в медицинских организациях города Курска и районов области. Научные ведомости Белгородско- 
го государственного университета. Серия: Медиицна. Фармация. 2019; 42(1):39-48 [Polshakova I.L., Povetkin S.V. Comparative multi-aspect characteristics of patients with atrial fibrillation, observing in medical organizations of the Kursk city and areas of the region. Belgorod State University Scientific Bulletin Medicine Pharmacy. 2019; 42(1):39-48 (in Russ.)] DOI: $\underline{10.18413 / 2075-4728-2019-42-1-39-48}$

6. Польшакова И.Л. Поветкин С.В. Структура лекарственной терапии и клиническая характеристика больных с фибрилляцией предсердий по данным исследования РЕКУР-ФП. Рациональная фармакотерапия в кардиологии. 2018; 14(5):733-740 [Polshakova I.L., Povetkin S.V. Drug therapy structure and clinical characteristics of patients with atrial fibrillation according to data of REKUR-AF study. $R a-$ tional Pharmacotherapy in Cardiology. 2018; 14(5):733-740. (in Russ.)] DOI: 10.20996/1819-64462018-14-5-733-740

7. Польшакова И.Л., Поветкин С.В., Чернышков Е.В. Система поддержки принятия фармакотерапевтических решений по антитромботической терапии больных с фибрилляцией предсердий в различных клинических ситуациях (СППР-ФП). Российская Федерация. Свидетельство о государственной регистрации программы для ЭBM RU 2017619104. 09 ноября 2017 г. [Polshakova I.L., Povetkin S.V., Chernyshkov E.V. Sistema podderzhki prinyatiya farmakoterapevticheskikh resheniy po antitromboticheskoy terapii bol'nykh s fibrillyatsiyey predserdiy $v$ razlichnykh klinicheskikh situatsiyakh (SPPR-FP). Russian Federation certificate of state registration of computer programs RU 2017619104. 2017 Nov 09 (in Russ.)]

8. Статистический ежегодник Курской области 2018. Курск: Курскстат, 2018. 424 с. [Statistical Yearbook of Kursk region 2018. Kursk: Kurskstat, 2018. 424 p. (in Russ.)]
9. Степина Е.В., Лукьянов М.М., Бичурина М.А., Белова Е.Н., Кудряшов Е.В., Юзьков Ю.В., Бойцов С.А. Назначение медикаментозной терапии, влияющей на прогноз у больных с фибрилляцией предсердий в сочетании с артериальной гипертонией, ишемической болезнью сердца, хронической сердечной недостаточностью по данным регистра РЕКВАЗА-КЛИНИКА. Кардиоваскулярная терапия и профилактика. 2017; 16(2):33-38 [Stepina E.V., Lukyanov M.M., Bichurina M.A., Belova E.N., Kudryashov E.V., Yuzkov Yu. V., Boytsov S.A. Prescription of medications influencing prognosis in atrial fibrillation with arterial hypertension, coronary heart disease, chronic heart failure, by the registry REKVAZA-CLINIC. Cardiovascular Therapy and Prevention. 2017; 16(2):33-38 (in Russ.)] DOI: $\underline{10.15829 / 1728-8800-2017-2-33-38}$

10. Территориальный орган Федеральной службы государственной статистики по Курской области. URL: https://kurskstat.gks.ru/publication_collection/docum ent/38734 (дата обращения 31.10.2019) [Territorial body of the Federal state statistics service in Kursk region. URL: https://kurskstat.gks.ru/publication_collection/docum ent/38734 (date of issue 31.10.2019) (in Russ.)]

11. Bassand J.P., Virdone S., Goldhaber S.Z., Camm A.J., Fitzmaurice D.A., Fox K.A.A., Goto S., Haas S. et al. Early risks of death, stroke/systemic embolism, and major bleeding in patients with newly diagnosed atrial fibrillation. Circulation. 2019; 139(6):787-798. DOI: $10.1161 /$ CIRCULATIONAHA.118.035012

12. Kirchhof P., Benussi S., Kotecha D., Ahlsson A., Atar D., Casadei B., Castella M., Diener H.C. et al. 2016 ESC Guidelines for the management of atrial fibrillation developed in collaboration with EACTS. Eur. Heart f. 2016; 37(38):2893-2692. DOI: $\underline{10.1093 / \text { eurheartj/ehw210 }}$

Поступила в редакцию 11.06.2019

Подписана в печать 19.09.2019

Для цитирования: Польшакова И.Л., Поветкин С.В. Отдаленные исходы и динамика фармакотерапии у пациентов с фибрилляцией предсердий по данным исследования РЕКУР-ФП. Курский научно-практический вестник «Человек и его здоровье». 2019; (3):5-11. DOI: 10.21626/vestnik/2019-3/01.

\section{LONG-TERM OUTCOMES AND DYNAMICS OF PHARMACOTHERAPY IN PATIENTS WITH ATRIAL FIBRILLATION ACCORDING TO THE REKUR-AF STUDY}

\section{(c) Polshakova I.L., Povetkin S.V.}

\section{Kursk State Medical University (KSMU)}

3, K. Marx St., Kursk, Kursk region, 305041, Russian Federation

The objective is to study the outcomes after 9 and 18 months in the framework of the REKUR-AF study and the dynamics of the drug treatment while implementing the components of the integrated approach in patients with atrial fibrillation $(\mathrm{AF})$ under the regional center.

Materials and methods. The study was conducted in three stages: 1 - inclusion of 896 patients with AF being observed in medical organizations (MO) of Kursk and Kursk region from September 2015 to August 2016; 2 - receiving information on outcomes and pharmacotherapy from patients by telephone contact 9 months after; 3 - receiving information 18 months after the recruitment of patients with the research similar to the second stage. After 9 months of follow-up, the sys- 
tem to support pharmacotherapeutic decisions on antithrombotic therapy in patients with AF (DSS-AF) was introduced in MO of Kursk Region.

Results. The 2 and 3 stages provided the information obtained on 532 and 436 patients, among them 60 and 37 people died, respectively. The cause of death of most patients is cardiovascular pathology. Among the surviving patients, every third needed hospitalization mainly due to decompensation of chronic heart failure or paroxysm of AF. After 18 months of observation, the frequency of prescribing antiplatelet drugs (57.1\%), angiotensin-converting enzyme inhibitors (55.6\%), statins (53.9\%) and diuretics (48.6\%) was significantly lower than in the first stage of the study. The level of using oral anticoagulants $(\mathrm{OAC}$ ) has significantly increased due to the period after the introduction of DSS-AF (from $18.3 \%$ of the stage 1 to $26.1 \%$ at the stage 3 of the work). In patients taking OAC, the frequency of fatal outcomes was significantly lower than in patients without anticoagulant therapy within 9 and 18 months of follow-up.

Conclusion. The paper shows the feasibility of using DSS-AF as a part of an integrated approach to the management of patients with AF to optimize the antithrombotic therapy of the indicated group of patients.

Keywords: atrial fibrillation; outcomes; regional research; therapy; integrated approach.

Polshakova Inna L. - Assistant of Department of Clinical Pharmacology, KSMU, Kursk, Russian Federation. ORCID iD: 0000-00025083-3137. E-mail: potolowa@mail.ru (correspondence author)

Povetkin Sergey V. - DM, Professor, Head of Department of Clinical Pharmacology, KSMU, Kursk, Russian Federation. ORCID iD: 0000-0002-1302-9326. E-mail: clinfarm@kursknet.ru

\section{CONFLICT OF INTEREST}

The authors declare the absence of obvious and potential conflicts of interest related to the publication of this article.

\section{SOURCE OF FINANCING}

The authors state that there is no funding for the study.

\section{CONFORMITY WITH THE PRINCIPLES OF ETHICS}

The study protocol was approved by the Ethical Committee under Kursk state medical university (Protocol No. 7 of 07.09.2015). Each patient signed the individual consent to participate in the study.

Received 11.06.2019

Accepted 19.09.2019

For citation: Polshakova I.L., Povetkin S.V. Long-term outcomes and dynamics of pharmacotherapy in patients with atrial fibrillation according to the REKUR-AF study. Kursk Scientific and Practical Bulletin "Man and His Health". 2019; (3):5-11. DOI: $10.21626 /$ vestnik/2019-3/01. 